1 Fundação Oswaldo Cruz (Fiocruz) - Brasília (DF), Brasil.

Orcid: https://orcid org/0000-0002-99059453

tereza.campello@gmail.com

2 Universidad de Buenos Aires (UBA) - Buenos

Aires, Argentina.

Orcid: https://orcid.

org/0000-0002-7607-

4167

pgentili@clacso.edu.ar

3 Pontifícia Universidade

Católica de São Paulo

(PUC-SP) - São Paulo (SP),

Brasil.

Orcid: https://orcid

org/0000-0001-5725-

9791

monica@zabele.net

4 Universidade Federal do

Rio Grande do Sul (UFRGS)

- Porto Alegre (RS), Brasil.

Orcid: https://orcid.

org/0000-0002-6140-

6800

gabrielrhoe@gmail.com

\section{Faces da desigualdade no Brasil: um olhar sobre os que ficam para trás}

\author{
Faces of inequality in Brazil: a look at those left behind
}

Tereza Campello', Pablo Gentili2, Monica Rodrigues $\mathbf{3}$, Gabriel Rizzo Hoewell4

DOI: $10.1590 / 0103-110420185305$

RESUMO Este artigo analisou avanços na redução das desigualdades no Brasil durante o período de 2003 a 2015, para além da perspectiva de renda. Os dados refletem que, embora transformações relevantes tenham ocorrido, mesmo assim, o Brasil persiste como um dos países mais desiguais do mundo. Entretanto, ao colocar uma lupa nos dados de acesso a bens e serviços dos $5 \%$ e dos 20\% mais pobres disponibilizados pela Pesquisa Nacional por Amostra de Domicílios (PNAD), os achados se contrapõem ao lugar comum de que só se promoveu acesso à renda e ao consumo dos mais pobres no período estudado, inexistindo alterações significativas no quadro de acesso a direitos básicos, políticas públicas de educação, saúde e de infraestrutura.

PALAVRAS-CHAVE Iniquidade social. Equidade. Renda. Pobreza.

ABSTRACT This article analyzed advances in the reduction of inequalities in Brazil during the period from 2003 to 2015, in addition to the income perspective. The data reflect that, although relevant transformations have occurred, nevertheless, Brazil persists as one of the most unequal countries in the world. However, by placing a magnifying glass on the data about access to goods and services of the poorest $5 \%$ and $20 \%$ made available by the National Household Sample Survey (PNAD), the findings contradict the commonplace that only access to income and the consumption of the poorest was promoted in the period studied, without significant changes in the framework of access to basic rights, public policies of education, health, and infrastructure.

KEYWORDS Social inequity. Equity. Income. Poverty. 


\section{Introdução}

O Brasil vivenciou uma inédita e sistemática queda da desigualdade no período recente, mas continua a ocupar a posição de um dos países mais desiguais do mundo. A expectativa, com os dados apresentados neste artigo, é mostrar como foi possível, em pouco mais de uma década, alterar situações de desigualdade dadas como irreversíveis e, principalmente, impactar o senso comum que naturaliza a pobreza e a desigualdade e que acaba por desmobilizar parte da sociedade na luta por direitos. $\mathrm{O}$ estudo que originou este artigo foi uma contribuição ao Programa Agenda Igualdade desenvolvido pela Faculdade Latino-Americana de Ciências Sociais, com apoio do Conselho Latino-Americano de Ciências Sociais e da Fundação Ford, e se tornou uma publicação, em novembro de 2017, com o título 'Faces da desigualdade no Brasil: um olhar sobre os que ficam para trás’’

A opção de análise aqui foi enfrentar as lacunas do debate sobre a desigualdade em países como o Brasil, onde uma parcela importante da população é excluída de direitos básicos. Propomos uma reflexão sobre a desigualdade como um fenômeno multidimensional e relacional, indo além de abordagens recorrentemente discutidas.

A mensuração de desigualdade mais conhecida é a da concentração de renda apurada pelo Coeficiente de Gini. Ela aponta a diferença entre os rendimentos dos mais pobres e dos mais ricos e vem cumprindo um papel inegável, ao expor uma das faces mais estruturantes do fenômeno, a desigualdade de renda. Entretanto, apresenta limitações por olhar um único aspecto do problema: a renda monetária.

Os dados do Coeficiente de Gini, todavia, são claros ao evidenciar uma queda na desigualdade de renda no período de 2002 a 2015, em patamares e com uma qualidade como não havia ocorrido na história brasileira. Durante o período, a riqueza acumulada no País aumentou e, ainda que a renda de todos os quintis tenha se ampliado significativamente, a renda dos mais pobres (primeiro e segundo quintis) aumentou mais do que a do resto da população. $\mathrm{O}$ processo reverteu uma tendência à concentração de renda que vivia o Brasil desde a ditadura militar e que ficou estagnada no início do período democrático. Entre 1980 e 2001, o Coeficiente de Gini ficou congelado no elevado patamar de 0,59, caindo, em 2015, ao seu nível mais baixo, 0,49 . O aumento real do salário mínimo, a crescente formalização do mercado de trabalho, a incorporação dos mais pobres ao orçamento federal, por meio de políticas de inclusão social e distribuição efetiva de renda, e a promoção de uma política social integrada explicam, em boa medida, essa transformação.

Dois estudos recentes ajudam a compor um campo de análise sobre o que ocorreu no Brasil. O estudo de Marc Morgan², utilizando metodologia desenvolvida por Piketty e Saez ${ }^{3}$, explicita os níveis históricos de desigualdade de riqueza no Brasil, combinando as informações do Imposto de Renda de Pessoa Física com as pesquisas domiciliares e as contas nacionais, e, neste caso, valorizando os dados do ponto de vista do patrimônio acumulado pelos ricos. Nesse sentido, tendem a refletir uma dimensão oculta que é a desigualdade de patrimônio, certamente maior que a de renda no Brasil. O estudo de Marc Morgan² revela que a concentração de riqueza no topo da pirâmide social entre 2001 e 2015 permaneceu inalterada.

No caso brasileiro e de países com uma expressiva parcela da população pobre, entretanto, o uso apenas da metodologia acima é insuficiente para explicar o que, de fato, ocorre com a camada mais vulnerável da população, por dois motivos: 1) na sua quase totalidade, esses instrumentos não captam a realidade nas faixas mais baixas de renda, e os pobres continuam, portanto, excluídos das estatísticas sobre desigualdade ou diluídos em uma abordagem geral; 2) o nível de exclusão a que estão submetidos não é só o de acumulação de riqueza, pois 
estão excluídos de praticamente todo o acesso a direitos, bens e serviços produzidos pelo conjunto da sociedade.

O outro estudo refere-se ao Relatório da Comissão sobre Medição do Desempenho Econômico e Progresso Social instituída pela União Europeia, coordenado por Joseph Stiglitz, Amartya Sen e Jean-Paul Fitoussi ${ }^{4}$, e apontam as limitações da comparação entre o Produto Interno Bruto e rendimentos entre países, em função dos distintos bens e serviços públicos assegurados aos cidadãos em diferentes contextos. Essa análise corrobora as preocupações apresentadas neste artigo. Os autores chamam a atenção para a dificuldade de comparar, por exemplo, gastos com saúde entre Estados Unidos da América (EUA) e França, serviço largamente privado no primeiro, e público no segundo. Nos levantamentos dos países que decidem ampliar a oferta pública de alimentação escolar, educação, saúde e assistência social, há que considerar a 'gratuidade' do acesso em relação à necessidade de compra de serviços nos demais países, em que essa oferta não é generalizada. Assim, a análise da desigualdade de renda pode não estar incorporando uma parte expressiva do bem-estar que não é comprado no mercado, mas que é provido pelo Estado.

É absolutamente importante discutir a desigualdade do ponto de vista da renda, olhando o estoque de capital e o patrimônio acumulado pelos ricos. No entanto, o olhar sobre a desigualdade não pode ignorar a necessidade de superar a assimetria de acesso a bens e serviços. Uma parcela expressiva da população vem vivendo à margem de condições mínimas de vida. Elevá-las a um patamar de dignidade não pode ser considerado um valor secundário no debate sobre desigualdade. Esse tema é, sem dúvida, um dos mais relevantes aprendizados e evidências do período de conquistas sociais que o Brasil viveu recentemente.

Assim, queremos adicionar ao escopo da análise econômica uma perspectiva mais humanizada sobre as faces que a desigualdade pode assumir em uma sociedade como a nossa, agregando empatia ao debate e ampliando uma visão crítica que apoie a compreensão sobre as múltiplas situações de privações de direitos e as políticas que podem contribuir estrategicamente para a mitigação das desigualdades. Há questões determinantes aqui. $\mathrm{O}$ acesso - ou o não acesso - à água, saneamento, energia, educação, saúde, moradia e bens de consumo, como geladeira, telefone, entre outros, não são dimensões periféricas da desigualdade. A urgência e a prioridade de acesso a esses direitos aos mais pobres podem ocorrer concomitantemente às mudanças estruturais que demandam tempo de implementação, ou seja, são a longo prazo.

O que para parte da população é um bem de consumo, para os mais pobres é um 'não direito' e um limitante, muitas vezes estrutural, às suas oportunidades de desenvolvimento e à possibilidade de uma vida digna e segura.

Uma visão reducionista da desigualdade conduz sempre a uma visão reducionista da emancipação e da liberdade humana. A busca pela desnaturalização da desigualdade passa pela conscientização de que se trata de um conjunto de injustiças. A desigualdade social é sempre uma relação política passível de ser enfrentada pela ação do Estado e afirmada pelas lutas coletivas por direitos, cujo efeito democrático pode ser desestabilizador de privilégios historicamente reproduzidos pelas elites.

\section{Considerações metodológicas}

Para construir os dados apresentados neste artigo, escolhemos dois recortes populacionais: os $5 \%$ e os $20 \%$ mais pobres comparados ao universo da população usando os dados da Pesquisa Nacional por Amostra de Domicílios (PNAD) 5 de 2002 a 2015, que utiliza para o cálculo dos indicadores dos mais pobres: o conjunto da população, 
exclusive moradores na condição de pensionistas, empregados domésticos e filhos de empregados domésticos, moradores de domicílios sem declaração de rendimentos e domicílios sem rendimento. A pergunta que orienta este olhar é: quem eram os $5 \%$ e os $20 \%$ mais pobres em 2002 e quem são agora?

A proposta foi adotar um indicador para enxergar os que estão no fim da fila, os esquecidos, levando em conta o que orienta a agenda 2030 das Nações Unidas - que 'ninguém seja deixado para trás'. Em cada recorte específico, elegemos dimensões que consideramos mais reveladoras das transformações referentes ao acesso a direitos.

Uma das referências utilizadas foi o painel do Banco Mundial6, que desenvolveu indicadores de pobreza crônica multidimensional. Essa metodologia detalhada por LopezCalva, Lachs e Fruttero ${ }^{7}$ considera aspectos além da renda e produz o índice de pobreza crônica multidimensional, que agrega três ou mais privações em cada uma das dimensões sociais: frequência escolar, escolaridade, saneamento, água segura, eletricidade, moradia e bens duráveis. São dimensões consideradas sensíveis na transição e vulnerabilidade em relação à pobreza.

Para proceder com nossa análise, adaptamos as variáveis à realidade brasileira, com as seguintes dimensões:

- Acesso à educação: adolescentes e jovens de 15 a 17 anos ao ensino médio; jovens de 18 a 24 anos ao ensino superior (graduação, mestrado e doutorado); chefes de família com ensino fundamental.

- Acesso a serviços de infraestrutura: água de qualidade; escoamento sanitário; energia elétrica.

- Acesso à habitação: moradia precária.

- Acesso a bens de consumo: geladeira ou freezer; máquina de lavar; celular; computador com internet.
Agregamos dados sobre saúde em um bloco à parte por ter uma fonte e uma base de análise diferenciadas. Os dados de mortalidade infantil tiveram como fonte o Sistema de Informação sobre Nascidos Vivos (Sinasc) 7 e o Sistema de Informações sobre Mortalidade (SIM) da Secretaria de Vigilância em Saúde do Ministério da Saúde. Já os dados de atendimentos de serviços de saúde são do Sistema de Informação em Saúde para a Atenção Básica (Siab/Sisab). Isso decorre do fato de que não há dados de saúde na PNAD nem dados administrativos na saúde que permitam análises com os recortes de renda. Entretanto, a saúde é fortemente determinada por condições sociais, econômicas e ambientais, como saneamento básico, moradia, trabalho, educação etc. Alguns de seus indicadores, como a mortalidade infantil, permitem avaliar aspectos das condições de vida da população mais vulnerável.

\section{Resultados}

Alguns elementos foram essenciais para a redução da desigualdade na forma que será apresentada. A escolha do período de 2002 a 2015 não é acidental. Este é um recorte de tempo em que um conjunto de decisões políticas - nas esferas social e econômica - visou à redução da pobreza e da desigualdade no Brasil.

Entre 2002 e 2015, foram 12 milhões de famílias negras cujos pais e mães passaram a ter ensino fundamental completo, 22 milhões de lares passaram a ter acesso à água de qualidade, e 24 milhões de domicílios, a possuir geladeira.

Nesse sentido, o conceito de bem de capital' é relativo quando, por exemplo, refletimos sobre o que é um investimento para um agricultor familiar pobre com uma pequena propriedade no semiárido brasileiro. Ter uma cisterna, acessar energia elétrica e dispor de crédito para sua produção podem significar a diferença entre passar fome ou não, manter-se em sua terra, produzir e 
viver com dignidade, gerar um excedente, ou abandoná-la acarretando mais pobreza nos grandes centros urbanos e mais concentração fundiária no campo. Esses bens não são contabilizados nas estatísticas que avaliam patrimônio e renda.

\section{Educação}

Se há um consenso em estratégia para o desenvolvimento de um país, este é o investimento em educação. A manutenção da desigualdade em educação é um dos fatores que mais determinam a dinâmica de exclusão e a perpetuação da pobreza. Escolhemos três indicadores que permitem depreender as transformações em curso na redução das desigualdades em educação relacionadas com os estratos mais pobres da população:
1) Avanço do número de jovens ingressando no ensino médio na idade certa; 2) Acesso ao ensino superior; 3) Pais e mães concluindo o ensino fundamental.

A análise do percentual da população de 15 a 17 anos que frequenta a escola no ensino médio ou etapa posterior (figura 1) é estratégica por ser uma variável de fluxo hipersensível às mudanças. Em 2002, somente 10,7\% dos jovens mais pobres ultrapassavam o muro dos que conseguiam chegar ao ensino médio na idade certa. Com o aumento de $264 \%$, este patamar chegou a $39 \%$.

Sabemos que continua baixo, mas mostra que prioridade estatal e política intensivas foram capazes de reverter um cenário em que o fracasso escolar dos pobres foi sempre naturalizado.

Figura 1. Percentual da população de 15 a 17 anos que frequenta escola no ensino médio ou etapa de ensino posterior, por faixa de renda, e de 18 a 24 anos que frequenta escola no ensino superior (inclusive mestrado e doutorado), por faixa de renda
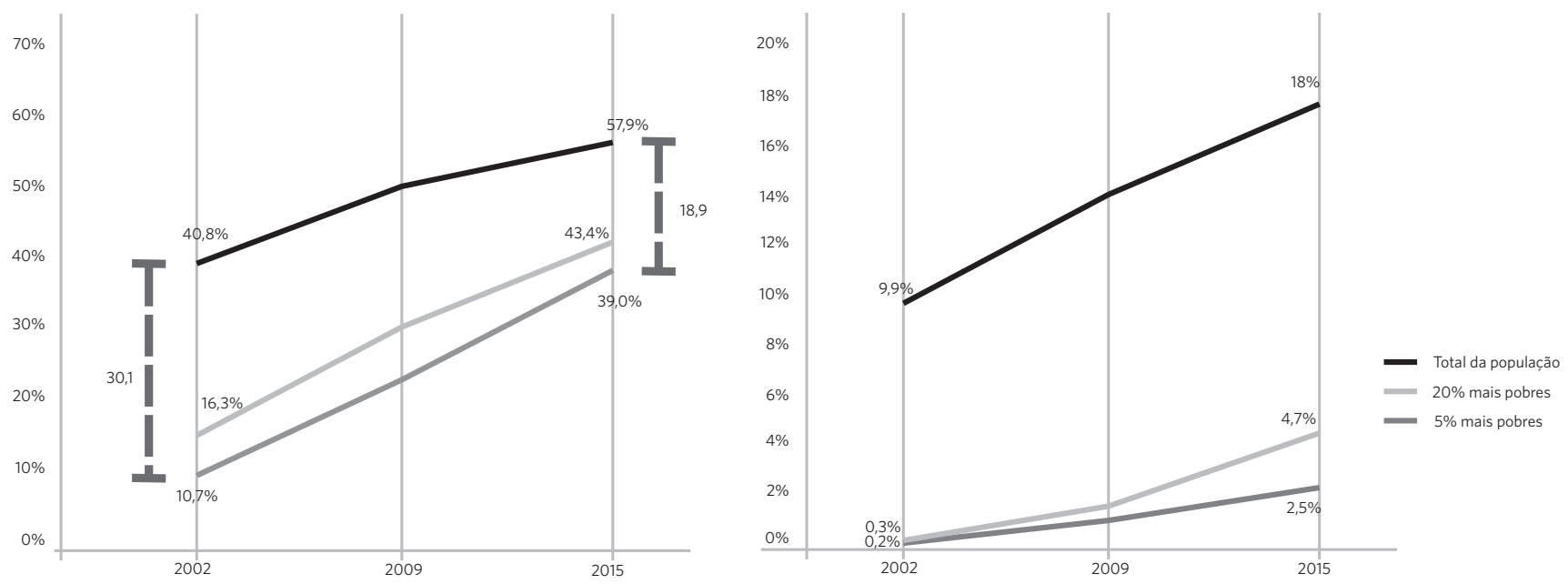

No período de 2002 a 2015, o acesso ao ensino superior, incluindo mestrado e doutorado, foi ampliado para toda a sociedade (figura 1). Enquanto o acesso ao conjunto da população quase dobrou, para os $20 \%$ mais pobres, ele foi multiplicado 23 vezes. Uma barreira histórica para estudantes das escolas públicas começou a ser rompida pelos jovens que enfrentam os desafios da desigualdade social, no entanto ainda é apenas uma brecha, que não comporta 
contingentes massivos de estudantes de baixa renda. $\mathrm{O}$ ensino superior continua sendo um espaço elitizado no Brasil.

Uma geração de jovens conquistou $\mathrm{o}$ lugar dos primeiros membros de suas famílias a terem acesso à universidade. Em 2015, por exemplo, $35 \%$ dos formandos que fizeram o Exame Nacional de Desempenho de Estudantes (Enade) eram os primeiros da família a serem diplomados.

Ter um dos adultos com ensino fundamental completo no domicílio é um dos requisitos estratégicos de resistência para a família não entrar em situação de pobreza crônica. Significa mais acesso à informação, aproveitamento de oportunidades, expansão do exercício de cidadania. A escolaridade da mãe é um dos determinantes na redução da mortalidade infantil e nas condições de aprendizagem dos filhos. Portanto, é um dos elementos que dimensionam a importância da evolução deste indicador e seus impactos. Em 2002, menos de 7\% dos mais pobres concluíam o ensino fundamental. Após 13 anos, esse índice passa para 30,3\%.

\section{Infraestrutura}

Em 2002, o acesso à água de qualidade chegava a quase $90 \%$ do total da população brasileira. Considerando que a água é um bem escasso no mundo, poderíamos supor que o Brasil estava em uma posição de ampla cobertura. Ao colocarmos a lente nos mais pobres, o quadro muda drasticamente: menos da metade $(49,6 \%)$ dos $5 \%$ mais pobres tinham garantia de acesso à água de qualidade.

No ano de 2015 , o percentual entre os $5 \%$ mais pobres progredira para $76 \%$. A ampliação beneficiou o conjunto dos brasileiros e foi 7 vezes mais rápida entre os $5 \%$ mais pobres, ou seja, enquanto para o total da população aumentou $7 \%$, para os mais pobres, foi ampliado em $53 \%$ (figura 2). Buscar simultaneamente atingir a universalização e a equidade foi a chave nesse processo. Políticas públicas inovadoras como cisternas, articuladas pelo Estado brasileiro, conseguiram mostrar que é possível alterar, em curto espaço de tempo, um quadro tão grave.

Figura 2. Percentual de domicílios particulares permanentes com acesso à água por rede geral, poço ou nascente com canalização interna, por faixa de renda, e percentual de domicílios particulares permanentes com energia elétrica, por faixa de renda
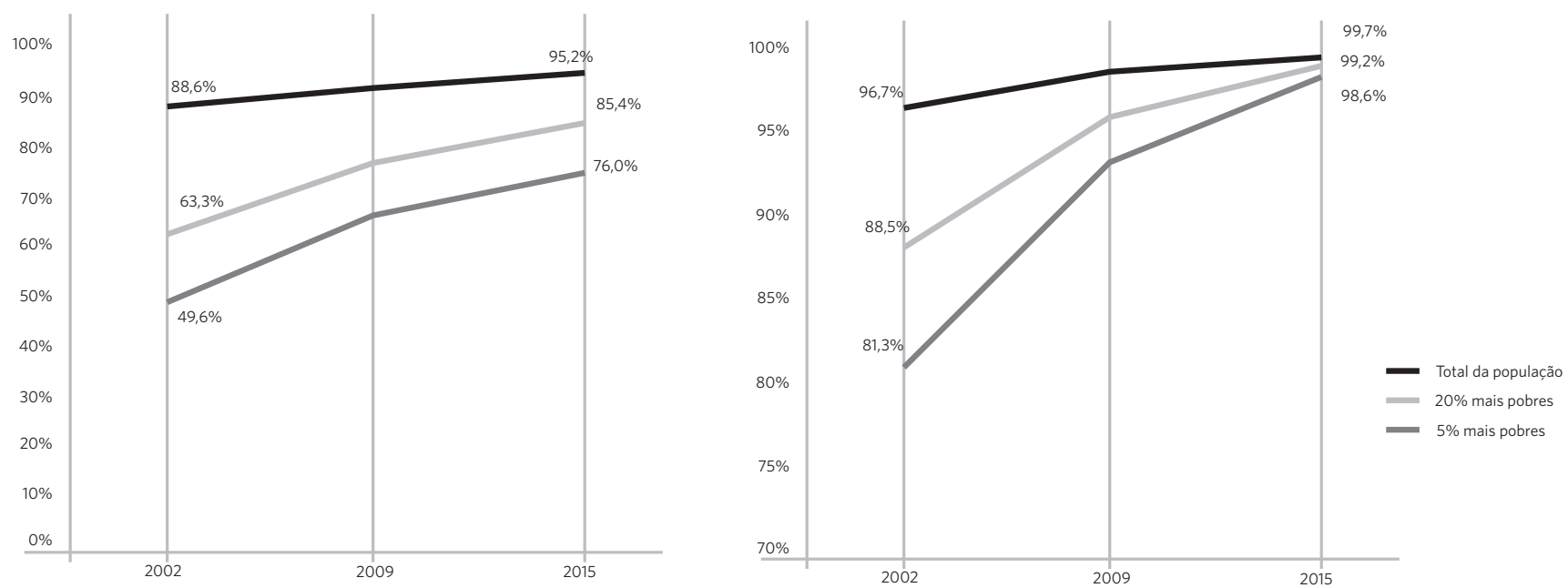
Saneamento é um dos investimentos públicos em infraestrutura mais dispendiosos e de longo tempo de maturação. Esse é um dos motivos que levam a não ser priorizado por muitos governos; e em raras situações observam-se profundas alterações no curto prazo. Por isso, é tão significativo ressaltar que o acesso ao escoamento sanitário mais do que dobrou entre os 5\% mais pobres entre 2002 e 2015, resultando em uma ampliação seis vezes mais rápida do que para o conjunto da população. Ou seja, enquanto para a população aumentou $18 \%$, para os mais pobres, o avanço passa de $114 \%$.

Para o universo da população, persiste, ainda no ano de 2015, a ausência de escoamento sanitário para 19,4\%. Além disso, mais grave, metade da população entre os $5 \%$ mais pobres continua sem acesso.

O Brasil alcançou, em 2002, a marca de apenas 3,3\% dos brasileiros sem energia elétrica. É um cenário que, avaliado por qualquer critério internacional, permitiria ao País anunciar a universalização do acesso a esse serviço. Um olhar acurado sobre a parcela mais pobre contradiz essa afirmativa. Nesse mesmo ano, quase $19 \%$ da população entre os $5 \%$ mais pobres não sabiam o que é conviver com eletricidade em suas casas (figura 2).

As barreiras de acesso à energia se concentravam na área rural, nas regiões Norte e Nordeste, entre as pessoas pobres e públicos específicos, como quilombolas ou moradores de áreas remotas. Comunidades inteiras conquistaram acesso à eletricidade, vendo as condições de vida e de bem-estar de suas famílias se transformarem instantaneamente.

O Brasil universalizou o direito à luz. Alguns públicos específicos em territórios isolados ainda remanescem, como o caso de comunidades extrativistas e quilombolas. $\mathrm{O}$ Estado terá que construir estratégias para chegar a esses territórios.

\section{Habitação}

O processo de urbanização excludente acirra as desigualdades e priva muitos brasileiros de ter um lar digno e de ter a esperança de uma vida mais segura. Um indicador que apoia a compreensão desse fenômeno é o de domicílios precários, que está concentrado entre as parcelas mais pobres da população.

Os dados da PNAD, no período de 2002 a 2015 , expõem a situação de $16,1 \%$ das famílias pertencentes aos $5 \%$ mais pobres, que residiam em domicílios precários, sem paredes de alvenaria, madeira ou revestimento adequado. Entre os mais pobres, o número de famílias por esse tipo de domicílio caiu para $7,5 \%$, sendo reduzido em mais de $50 \%$ e beneficiando lares chefiados por mulheres e negros. Essa realidade começou a ser alterada em compasso com as demandas dos movimentos de luta por moradia, por meio de um conjunto de políticas, em especial a urbanização de favelas e programas como o Minha Casa Minha Vida. É fundamental considerar, também, o aumento da renda dos mais pobres, que permitiu um amplo e silencioso processo de benfeitorias, reformas e ampliação nos imóveis particulares.

\section{Bens de consumo}

Bens duráveis, como geladeira e máquina de lavar, constituem-se em itens básicos para o funcionamento de uma casa em qualquer lugar. Um contingente representativo de famílias pobres brasileiras passou a conhecer as comodidades de seus usos somente na última década.

É notável o crescimento de acesso a esses bens no período de 2002 a 2015, que, distante de constituir um comportamento consumista, representa melhorias objetivas, liberação de tempo gasto em tarefas domésticas, melhoria na autoestima das famílias e ampliação das possibilidades de acesso a outras oportunidades. É o caso do telefone celular e do computador com acesso à internet, que deixam de ser privilégio de uma parte do Brasil e passam a compor o dia a dia das famílias negras e dos mais pobres. 
Um fenômeno a ser valorizado nessa inclusão são os milhões que passam a integrar o consumo, concorrendo para a dinamização do mercado interno.

Em 2002, o acesso a refrigerador ou freezer chegava somente a 44,1\% dos lares mais pobres. $\mathrm{O}$ crescimento nesse segmento foi exponencial, passando para 91,2\% (figura 3). A ampliação da renda e do crédito, a desoneração da linha branca e a chegada do Programa Luz para Todos em territórios sem energia elétrica explicam parte do aumento das aquisições desse bem durável pelas camadas mais pobres.

Figura 3. Percentual de domicílios particulares permanentes com geladeira ou freezer, por faixa de renda, percentual de domicílios particulares permanentes com máquina de lavar, por faixa de renda, e percentual de pessoas de referência dos domicílios com posse de telefone celular, por faixa de renda
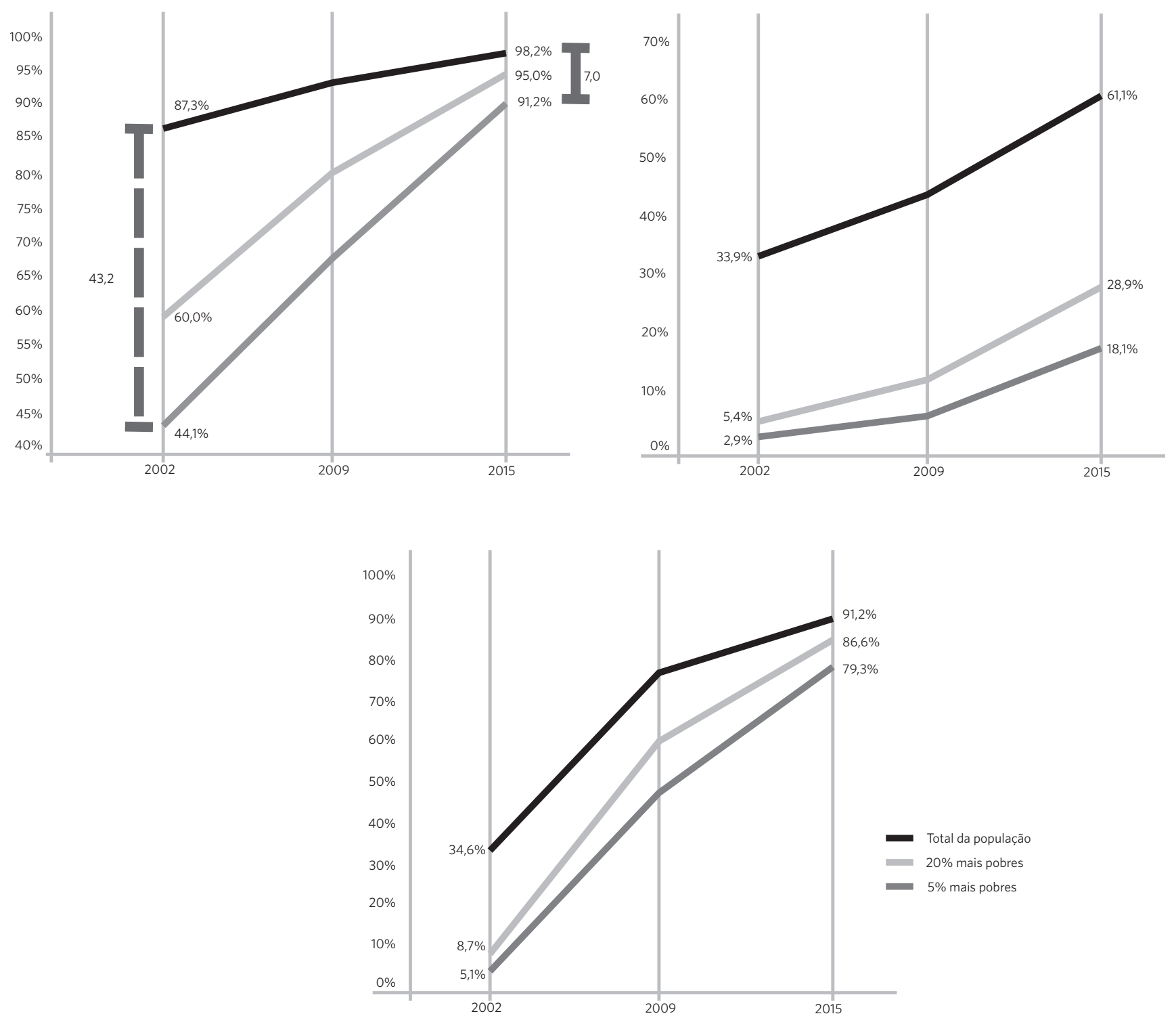
Foi significativa a ampliação de lares no Brasil com máquina de lavar roupa no período de 2002 a 2015, sendo que o maior crescimento ocorreu entre os $5 \%$ e os $20 \%$ mais pobres. No ano de 2015 , constata-se que $18,1 \%$ dos domicílios mais pobres contavam com esse bem de consumo, sendo ainda um patamar muito baixo (figura 3). É uma situação que indica a dificuldade presente das famílias pobres em adquirir um item determinante no uso do tempo dedicado aos afazeres domésticos, principalmente das mulheres.

A desigualdade de acesso a bens de consumo entre brancos e negros fica evidente, e vai além da questão de renda. Analisando a população brasileira em sua totalidade, observamos que enquanto 42 milhões de pessoas brancas residiam em domicílios com máquina de lavar em 2002, entre as famílias de cor negra, eram apenas 15 milhões, mesmo sendo maioria na população. Entre 2002 e 2015, o aumento garantiu que novos 40 milhões de negros e negras alcançassem essa comodidade.

A inclusão digital é um dos principais vetores de acesso à informação. Nesse aspecto, o Brasil de 2002 sofreu uma mudança impressionante em relação a 2015, sendo observada a alteração no padrão de consumo de bens duráveis dos brasileiros, seguindo o ritmo das mudanças tecnológicas. $\mathrm{O}$ acesso a telefones celulares e, nos últimos anos, a aparelhos com conectividade e múltiplas funções é expressão desse comportamento (figura 3).

A maior presença de computadores nos domicílios também é verificada, mas em menor intensidade em todas as classes sociais, refletindo o processo de substituição de tecnologias ante as novas funcionalidades dos telefones celulares.

O acesso aos celulares foi uma das situações que mais proporcionalmente se igualaram em todas as faixas de renda. A presença dos aparelhos entre os 5\% mais pobres cresceu de 5,1\% em 2002 para 79,3\% em 2015; e entre os $20 \%$ mais pobres, o índice foi de $8,7 \%$ para $86,6 \%$, muito próximo ao do total de domicílios, que atingiu $91,2 \%$. Os telefones celulares atualmente representam mais do que um instrumento de comunicação e informação. Para os mais pobres, eles carregam a possibilidade de ampliar o acesso a novas oportunidades, incrementar empreendimentos e renda, além de garantir segurança para os membros da família.

\section{Saúde}

A saúde é um reflexo direto das condições socioeconômicas da população. O crescimento desordenado das cidades, a falta de saneamento básico e água de qualidade, as condições de moradia e de trabalho, a alimentação, a educação, questões étnicas/ raciais, aspectos vistos até agora neste trabalho enquanto dimensões da desigualdade, são fortes Determinantes Sociais de Saúde.

Alguns indicadores de saúde podem ser considerados resultantes diretos das demais políticas públicas, ou da ausência delas. Mortalidade infantil (em crianças menores de 1 ano) certamente é o mais marcante (figura 4). $\mathrm{O}$ indicador vem caindo de forma sistemática no Brasil. De 2002 a 2015, saiu de 23,4 por mil nascidos vivos para 12,9 . Os valores até $20 / \mathrm{mil}$ nascidos vivos estão na faixa considerada baixa pela Organização Mundial de Saúde.

A queda foi mais acentuada no Norte e no Nordeste, exatamente onde os índices eram maiores, e onde mais se ampliaram as políticas públicas, como vimos anteriormente. É um indicador síntese do esforço bem-sucedido de redução da pobreza, de acesso à água, da ampliação da escolaridade das mães, entre outros fatores. 
Figura 4. Taxa de mortalidade infantil no Brasil e por região (por 1.000 nascidos vivos) e média anual de atendimentos médicos e de enfermagem por habitante na atenção básica
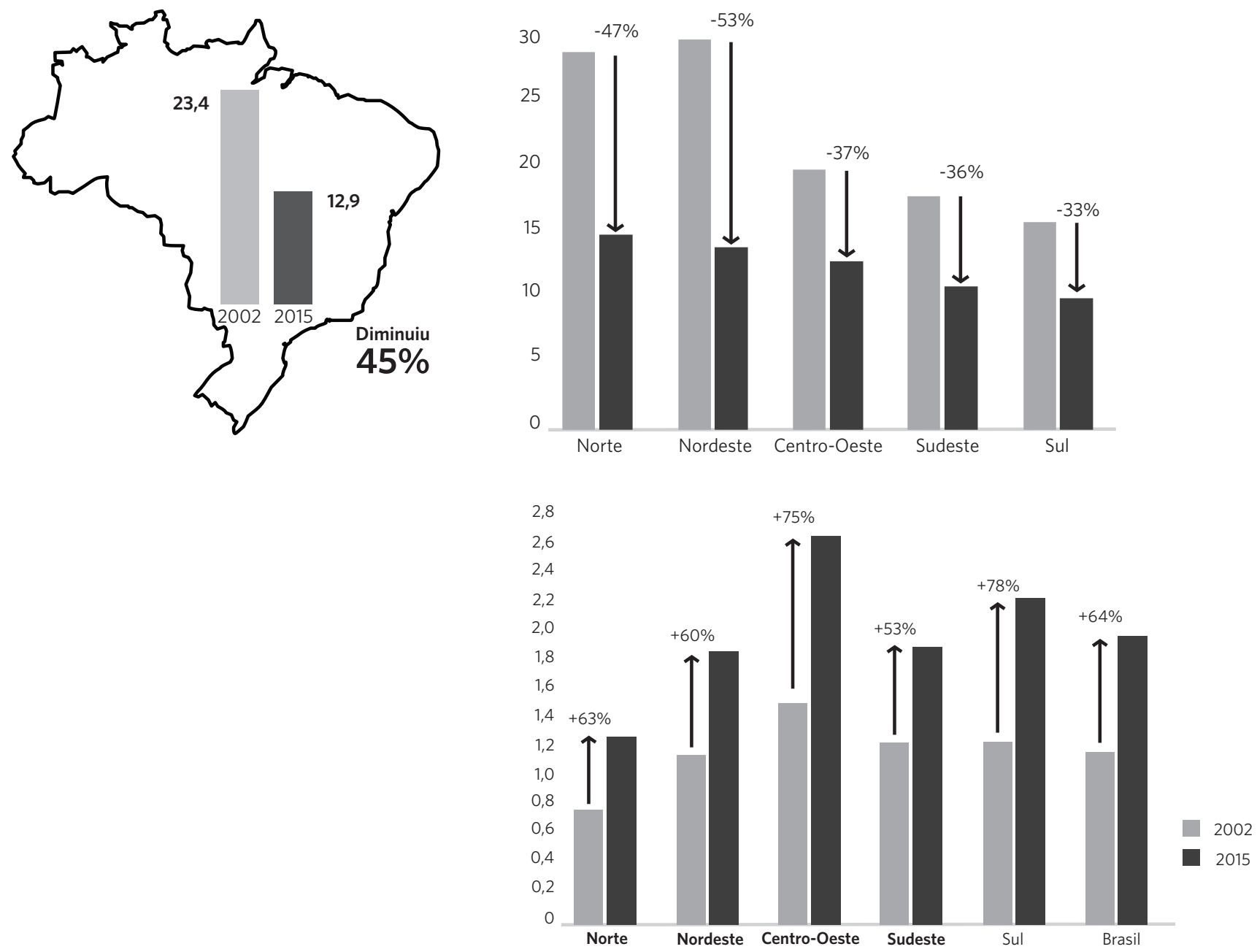

Fonte: Sinasc/SIM? 2015.

Além disso, em 2002, a cobertura populacional em atenção básica era de $31,8 \%$, e, em 2015, passou para $63,2 \%$. Associada à forte expansão, as políticas de saúde passaram a reconhecer especificidades geradas pelas situações de vulnerabilidade social e exigiram novos modelos de organização dos serviços.

Iniciativas como o Programa Mais Médicos, os Núcleos de Apoio à Saúde da Família (Nasf), os Consultórios na Rua, as Unidades Básicas Fluviais de Saúde, as Unidades Móveis de Saúde Bucal, a Política Nacional de Saúde Integral da População Negra, entre outras, somaram-se à expansão da rede e ao aumento dos atendimentos no Sistema Único de Saúde. Essas estratégias chegaram a diferentes públicos, que permaneciam excluídos dos esforços de universalização da cobertura de serviços (figura 4). 


\section{Conclusões}

Transitamos até aqui por diversos indicadores que permitiram aferir a queda da desigualdade em múltiplas faces entre 2002 e 2015. A opção de apresentar um indicador de desigualdade de renda na parte final deste artigo não é fortuita. A discussão sobre renda, em geral, monopoliza os debates sobre pobreza e desigualdade, mesmo entre os que defendem uma avaliação multidimensional.

O recorte utilizado ao longo da publicação, os $5 \%$ e os $20 \%$ mais pobres comparados ao total da população, é ainda mais revelador do crescimento acima da média da renda dos mais pobres. É inegável a redução da desigualdade de renda usando os dados da PNAD. O crescimento real da renda do conjunto da população chegou a $38 \%$ e foi ainda mais acentuado entre os mais pobres. A renda dos $20 \%$ mais pobres cresceu quase 4 vezes mais rápido que a dos $20 \%$ mais ricos (figura 5). A ampliação acima da inflação ocorreu para todas as faixas de renda, apesar dos efeitos da crise econômica que já se fizeram sentir a partir de 2012.

Figura 5. Variação percentual do rendimento médio domiciliar per capita real entre 2002 e 2015, por quintis de renda

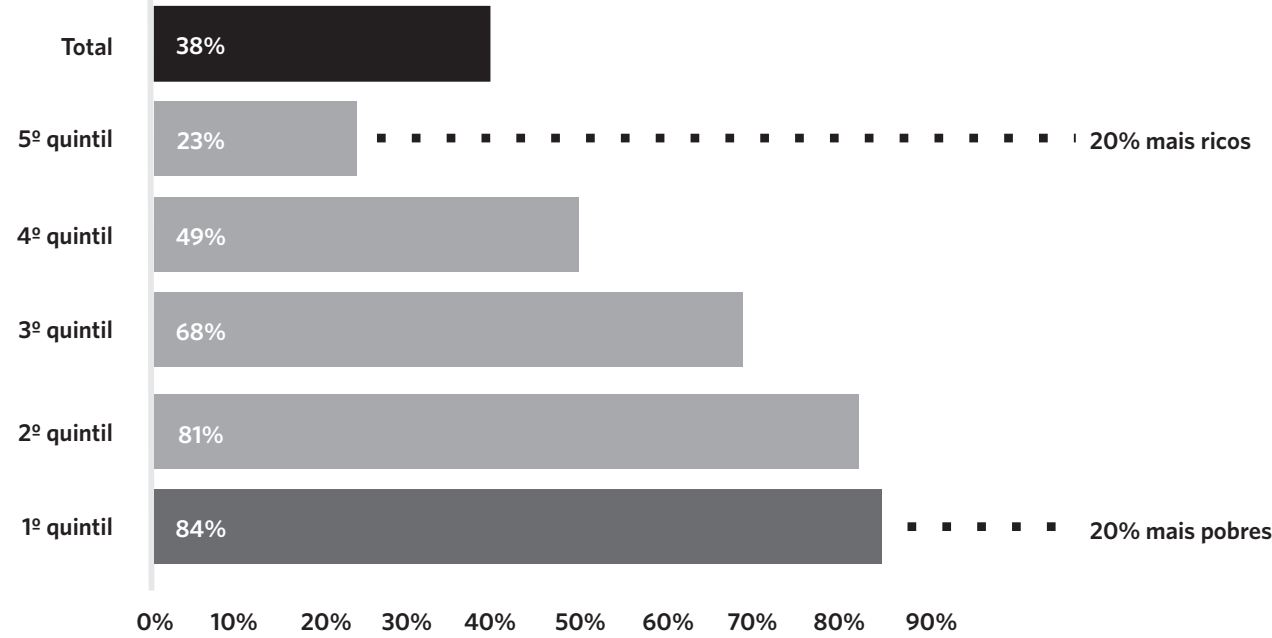

Fonte: IBGE/PNAD 5

A ampliação da renda, que se refletiu em mais direitos, mais acesso e, sim, mais consumo, é resultado direto da política de valorização do salário mínimo, formalização do trabalhador, criação de novos empregos - inclusive os decorrentes de investimentos como habitação popular, equipamentos sociais e política de conteúdo nacional -, ampliação do acesso à aposentadoria urbana e rural, benefícios assistenciais e do Bolsa
Família. A consequência direta desse processo foi o fortalecimento do mercado interno.

A expansão dos investimentos em infraestrutura foi direcionada para chegar às periferias, aos bairros operários e ao campo. Fomos buscar nos indicadores de água, saneamento e energia como isso se reflete para os que historicamente ficaram para trás.

A busca da universalização e do enfrentamento das iniquidades em educação, saúde e 
assistência social, prevista desde a Constituição Federal de 1988, ousou tocar na franja marginalizada da sociedade; e a resposta foi imediata: milhões de jovens na escola na idade certa, jovens negros e negras nas universidades, queda vertiginosa da mortalidade infantil.

Ao colocar uma lupa sobre os $5 \%$ e os $20 \%$ mais pobres da sociedade brasileira e perceber o processo silencioso de inclusão e redução de parte importante das desigualdades ocorridas, esta perspectiva não se encerra em si mesma, mas se soma às demais abordagens que buscam compreender os caminhos para se trilhar a redução das desigualdades. Há muitos desafios e muitas dívidas ainda pendentes.

Este artigo joga luz sobre o que ocorreu entre 2002 e 2015, evidenciando os resultados decorrentes das políticas públicas e que estabeleceram novos patamares para a agenda brasileira de combate à pobreza e de enfrentamento às desigualdades. Os avanços do período foram fruto de decisão política, afastando a aceitação de uma condenação natural e inevitável à desigualdade. Registrar que continuamos sendo uma nação extremamente desigual não é suficiente. A desigualdade do Brasil pode e exige ser mudada.

\section{Colaboradores}

Campello $\mathrm{T}$ contribuiu para a análise e interpretação dos dados, revisão crítica do conteúdo e aprovação da versão final do manuscrito. Gentili P contribui significativamente para a elaboração, redação e revisão do artigo, aprovando sua versão final. Rodrigues $\mathrm{M}$ contribuiu para a concepção, planejamento, análise e interpretação dos dados. Hoewell GR contribuiu para a análise e interpretação dos dados, revisão crítica do conteúdo e aprovação da versão final do manuscrito. 


\section{Referências}

1. Campello T. Faces da desigualdade no Brasil: um olhar sobre os que ficam para trás. Brasília, DF: Faculdade Latino-Americana de Ciências Sociais; Conselho Latino-Americana de Ciências Sociais; 2017.

2. Morgan M. Income Inequality, Growth and Elite Taxation in Brazil: New Evidence Combining Survey and Fiscal Data, 2001-2015 [internet]. In: 70. Meetingof the Society for the Study of Economic Inequality. 2017 [acesso em 2018 set 25]. p. 1-11. Disponível em: http://www.ecineq.org/ecineq_nyc17/ FILESx2017/CR2/p456.pdf.

3. Piketty T, Saez E. Income inequality in the United States 1913-1998. Quarterly J Econom. 2013 fev; 118(1):1-41.

4. Stiglitz J, Sen A, Fitoussi JP. Relatório da Comissão sobre a Mensuração de Desempenho Econômico e Progresso Social. Curitiba: SESI/PR; 2012.

5. Instituto Brasileiro de Geografia e Estatística. Pes- quisa Nacional por Amostra de Domicílios. Rio de Janeiro: IBGE; 2015.

6. World Bank Group. The State of Social Safety Nets 2015 [internet]. Washington: Disponível em: World Bank Group; 2015 [acesso em 2017 jul 31]. Disponível em: https://bit.ly/2M6arhL.

7. Lopez-Calva L, Lachs S, Fruttero A. Medir pobreza crônica no Brasil. Cad Estudos Desenvol Social Debate [internet]. 2015 [acesso em 2018 ago 5]; (21):140-160. Disponível em: https://aplicacoes.mds.gov.br/sagirmps/ferramentas/docs/Caderno\%20de\%20Estudos\%2021_COMPLETA.pdf.

8. Sistema Único de Saúde. Sistema de Informações de Nascidos Vivos. Brasília, DF: Datasus; 2015.

Recebido em 01/08/2018

Aprovado em 09/09/2018

Conflito de interesses: inexistente

Suporte financeiro: não houve 